УДК 331.101 .52

$10.17213 / 2075-2067-2020-4-37-45$

\title{
МЕТОДЫ ОЦЕНКИ УПРАВЛЕНИЯ \\ НАУЧНО-ИССЛЕДОВАТЕЛЬСКОЙ ДЕЯТЕЛЬНОСТЬЮ УНИВЕРСИТЕТОВ В РОССИЙСКОЙ И МИРОВОЙ ПРАКТИКЕ
}

\author{
(C) 2020 г. Н. Л. Кетоева, М. А. Киселева, В. К. Котельная
}

Национальный исследовательский университет «МЭИ», г. Москва, Россия

Целью исследования является анализ методов управления научно-исследовательской деятельностью российских и мировых университетов, а также выделение отличительных показателей оченки для российских университетов.

Методологическую базу исследования составили методы:: диалектического научного познания и частные научные (анализ, синтез, сравнение, логический и системно-структурный анализ, формализация, анализ нормативно-правовых документов), моделирование.

Результаты исследования помогут оптимизировать управление научно-исследовательской деятельностью и вносить изменения в существующую нормативно-правовую документацию университета.

Перспектива исследования. Выделенные показатели оценки научно-исследовательской деятельности университетов сформируют методы оценки деятельности научных групп университета.

Ключевые слова: научно-исследовательская деятельность; методы оценки научноисследовательской деятельности; показатели управления научно-исследовательской деятельности в российской и международной практике.

\section{METHODS FOR EVALUATING THE MANAGEMENT OF RESEARCH ACTIVITIES OF UNIVERSITIES IN RUSSIAN AND INTERNATIONAL PRACTICE}

\author{
(C) 2020 N. L. Ketoeva, M. A. Kiseleva, V. K. Kotelnaya \\ National Research University «MPEI», Moscow, Russia
}

The purpose of the study is to analyze the methods for managing the research activities of Russian and world universities, as well as to identify distinctive assessment indicators for Russian universities.

The methodological base of the study was made up of methods: dialectical scientific knowledge and private scientific (analysis, synthesis, comparison, logical and system-structural analysis, formalization, analysis of legal documents), modeling.

The results of the study will help optimize the management of research activities and make changes to the existing regulatory documentation of the university.

The prospect of the study. The distinguished indicators for evaluating the research activities of universities will form methods for assessing the activities of university research groups.

Key words: research activity; methods of evaluation of research activity; indicators of management of research activity in Russian and international practice. 
Введение. Экономическая и политическая обстановка, которая сложилась в мире, и рост темпов развития научно-технического процесса позволяют считать образование и конкурентоспособный человеческий капитал наиболее важными ресурсами развития страны. Трансформация высшего образования в России в многоуровневую систему подготовки, а также увеличение требований со стороны работодателей к выпускникам высших учебных заведений создают потребность изменять содержание подготовки специалистов, бакалавров, магистров и аспирантов, сферой профессиональной деятельности которых является система высшего образования. Эти изменения нашли отражение в образовательных стандартах третьего поколения, в их основу положен компетентностный подход, который ориентирует участников процесса образования на формирование компетенций — качеств личности, которые необходимы для самостоятельного ведения профессиональной, а также исследовательской деятельности. [2]

Будущий специалист должен объединять в себе способности ученого, конструктора и менеджера, кроме этого, он должен уметь объединять специалистов различного профиля для совместной работы. Таким образом, в настоящее время интерес для общества и работодателя на рынке труда представляет выпускник, закончивший высшее учебное заведение, который нацелен на поиск творческих решений для профессиональных задач, т.е. владеющий на высоком уровне професси- онально-творческими компетенциями. В федеральных государственных образовательных стандартах высшего образования (ФГОС ВО) научно-исследовательская деятельность содержится в профессиональной подготовке специалистов, бакалавров, магистров и аспирантов и способствует профессионально-творческому развитию студентов, выступая в качестве площадки для эффективной коммуникации субъектов образовательного процесса и обеспечивая реализацию социального заказа для подготовки компетентного профессионала. По данным федеральной службы государственной статистики, количество учреждений, занимающихся научной деятельностью, с каждым годом имеет тенденцию к снижению $(4175,4032$ и 3944 за последние годы) [10].

Вышеизложенная информация свидетельствует о том, что необходимо развивать научную деятельность [6], а для развития необходимо проведение качественной оценки научно-исследовательской деятельности с целью выявления ее слабых сторон.

Методы оценки управления научноисследовательской деятельностью в российской практике. На текущий момент вопрос эффективного функционирования вуза стал одним среди наиболее часто обсуждаемых в научном сообществе. Политика Минобрнауки РФ в сфере высшего образования подталкивает вузы более внимательно относиться к эффективности деятельности и концентрировать основные усилия на достиже-

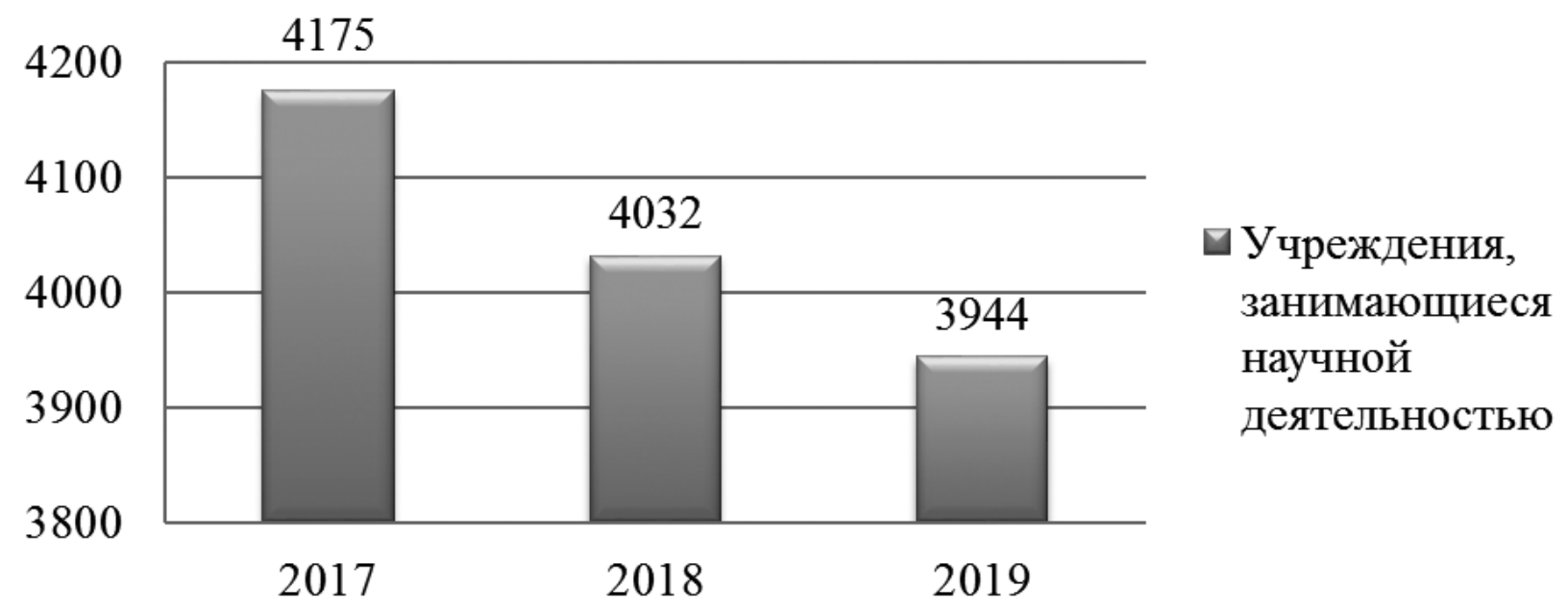

Рис. 1. Статистика количества учреждений, занимающихся научной деятельностью, за 2017-2019 гг. 
нии определенных задач, которые получили отражение в системе показателей эффективности вуза.

Эффективное управление научно-исследовательской деятельностью представляет собой наиболее приоритетную задачу для руководства вуза на всех уровнях управления, а также содержит в себе планирование, организацию, контроль, координацию и активизацию научных исследований:

- в целом университета;

- структурных подразделений, которые есть в университете, а именно - институтов;

- студентов и аспирантов университета [5].

Оценка управления научно-исследовательской деятельностью вуза возможна только лишь через совокупность результативных и ресурсных показателей, а также показателей системной эффективности. Иначе говоря, эффективное управление научно-исследовательской деятельностью определяется через эффективность самой научно-исследовательской деятельности.

В российской и зарубежной практике существуют различные методики оценки научно-исследовательской деятельности. Рассмотрим некоторые из них.

Наиболее важной методикой, которая применяется в российской практике, является система оценивания научно-исследовательской деятельности университета, которую проводит Департамент государственной политики в сфере высшего образования и молодежной политики Министерства науки и высшего образования Российской Федерации.

Главный информационно-вычислительный центр ежегодно проводит анализ деятельности вузов и публикует информационно-аналитические материалы по результатам проведения мониторинга на своем сайте [9].

Система оценивания включает в себя следующие показатели, которые представлены в таблице 1.

$\mathrm{K}=$ Maх обозначает, что показатели вузов региона за отчетный период стремятся к максимуму.

$\mathrm{K}_{\mathrm{n}}-\mathrm{K}_{\mathrm{n}-1} \geq 0$ обозначает, что показатели вузов региона за отчетный период должны быть равными или большими, чем значение показателей в прошлом периоде.

На основании данных, представленных в системе показателей, можно осуществлять диагностику управления научно-исследовательской деятельностью университета, реализовывать планирование по ее развитию, обеспечивать выполнение и проводить оценку достигнутых результатов.

Рассмотрим еще одну методику оценки системы управления деятельностью университета. Данная методика основана на теории графов. Ее главная особенность - возможность учитывать согласованность структуры управления с системой целей университета [3].

В рамках данного исследования рассматривается система управления научно-исследовательской деятельностью университета. В системе целей методики рассмотрим цель S4 — «Развитие научно-исследовательской и инновационной деятельности». К подцелям данной системы относятся: организация научно-исследовательской деятельности студентов и преподавателей, публикации научных трудов, выполнение НИОКР, осуществление развития кадрового потенциала научно-исследовательской и инновационной деятельности, передача авторских прав и коммерциализация результатов научно-исследовательской деятельности, а также выполнение грантов и государственных заданий.

Стоит отметить, что оценку эффективности научно-исследовательской деятельности можно осуществлять на основе двух критериев:

- качество научно-исследовательских работ, проводимых в университете;

- соответствие научно-исследовательских работ проблемной ориентации университета.

Для точного анализа научно-исследовательской деятельности следует формировать систему показателей, которые определяют общий научный потенциал, а также перспективы развития научной деятельности университета. Уделим внимание следующим показателям, которые характеризуют научную деятельность в университете:

- деятельность в аспирантуре и докторантуре, а также деятельность по повышению научной квалификации;

- научно-исследовательская деятельность;

- деятельность по изданию научных работ, конференции;

- научная деятельность, относящаяся к защитам диссертаций;

- организация научно-исследовательской работы студентов [7]. 


\section{Система оценивания научно-исследовательской деятельности Департамента государственной политики в сфере высшего образования и молодежной политики}

\begin{tabular}{|c|c|c|c|}
\hline № & Показатель & Ед. изм-я & Критерий \\
\hline 1 & $\begin{array}{l}\text { Объем цитирований публикаций, которые изданы за последние } \\
\text { пять лет и индексируются в информационно-аналитической } \\
\text { системе научного цитирования Web of Science Core Collection в } \\
\text { расчете на } 100 \text { НПР }\end{array}$ & Ед. & $\mathrm{K}=\mathrm{Max}$ \\
\hline 2 & $\begin{array}{l}\text { Объем цитирований публикаций, которые изданы за последние } \\
\text { пять лет и индексируются в информационно-аналитической } \\
\text { системе научного цитирования Scopus в расчете на } 100 \text { HПР }\end{array}$ & Ед. & $\mathrm{K}=\mathrm{Max}$ \\
\hline 3 & $\begin{array}{l}\text { Объем цитирований публикаций, которые изданы за последние } \\
\text { пять лет и индексируются в информационно-аналитической } \\
\text { системе научного цитирования, РИНЦ в расчете на } 100 \text { НПР }\end{array}$ & Ед. & $\mathrm{K}=\operatorname{Max}$ \\
\hline 4 & $\begin{array}{l}\text { Количество публикаций организации, которые индексируются в } \\
\text { информационно-аналитической системе научного цитирования } \\
\text { Web of Science Core Collection на } 100 \text { НПР }\end{array}$ & Ед. & $\mathrm{K}=\mathrm{Max}$ \\
\hline 5 & $\begin{array}{l}\text { Количество публикаций организации, которые индексируются в } \\
\text { информационно-аналитической системе научного цитирования } \\
\text { Scopus на } 100 \text { HПР }\end{array}$ & Ед. & $\mathrm{K}=\mathrm{Max}$ \\
\hline 6 & $\begin{array}{l}\text { Количество публикаций организации, которые индексируются в } \\
\text { информационно-аналитической системе научного цитирования } \\
\text { РИНЦ на } 100 \text { НПР }\end{array}$ & Ед. & $\mathrm{K}=\mathrm{Max}$ \\
\hline 7 & $\begin{array}{l}\text { Совокупный объем научно-исследовательских и опытно-конс- } \\
\text { трукторских работ (НИОКР) }\end{array}$ & Тыс. p. & $\mathrm{K}=\operatorname{Max}$ \\
\hline 8 & $\begin{array}{l}\text { Удельный вес доходов от НИОКР в общих доходах образова- } \\
\text { тельной организации }\end{array}$ & $\%$ & $\mathrm{~K}=\mathrm{Max}$ \\
\hline 9 & $\begin{array}{l}\text { Удельный вес НИОКР, которые выполнены собственными сила- } \\
\text { ми, в общих доходах образовательной организации }\end{array}$ & $\%$ & $\mathrm{~K}=\operatorname{Max}$ \\
\hline 10 & $\begin{array}{l}\text { Доходы от НИОКР (кроме средств бюджетов бюджетной систе- } \\
\text { мы РФ и государственных фондов поддержки науки) в расчете } \\
\text { на одного НПР }\end{array}$ & Тыс. p. & $\mathrm{K}=\mathrm{Max}$ \\
\hline 11 & Число лицензионных соглашений & Ед. & $\mathrm{K}_{\mathrm{n}}-\mathrm{K}_{\mathrm{n}-1} \geq 0$ \\
\hline 12 & $\begin{array}{l}\text { Удельный вес средств, которые получены образовательной ор- } \\
\text { ганизацией от использования результатов интеллектуальной де- } \\
\text { ятельности, в общих доходах образовательной организации }\end{array}$ & $\%$ & $\mathrm{~K}=\mathrm{Max}$ \\
\hline 13 & $\begin{array}{l}\text { Удельный вес численности НПР без ученой степени - до } 30 \text { лет, } \\
\text { кандидатов наук - до } 35 \text { лет, докторов наук —до } 40 \text { лет, в об- } \\
\text { щей численности НПР }\end{array}$ & $\%$ & $\mathrm{~K}=\mathrm{Max}$ \\
\hline 14 & $\begin{array}{l}\text { Удельный вес НПР, которые защитили кандидатские и докторс- } \\
\text { кие диссертации за отчетный период в общей численности НПР }\end{array}$ & $\%$ & $\mathrm{~K}_{\mathrm{n}}-\mathrm{K}_{\mathrm{n}-1} \geq 0$ \\
\hline 15 & $\begin{array}{l}\text { Число научных журналов, в том числе электронных, которые из- } \\
\text { дает образовательная организация }\end{array}$ & Ед. & $\mathrm{K}_{\mathrm{n}}-\mathrm{K}_{\mathrm{n}-1} \geq 0$ \\
\hline 16 & Число полученных грантов за отчетный год в расчете на 100 НПР & Ед. & $\mathrm{K}_{\mathrm{n}}-\mathrm{K}_{\mathrm{n}-1} \geq 0$ \\
\hline
\end{tabular}


Отметим, что при подборе показателей оценки следует учитывать 5 главных критериев:

- значимость - связь с целями и задачами вуза;

- надежность - упор на последовательные и сопоставимые данные

- возможность осуществления аудита данных - данные должны быть проверяемы;

— прозрачность - данные должны однозначно толковаться;

- своевременность - данные по индикаторам должны обладать доступностью по графику проведения оценивания [8].

Авторы научных трудов выделяют следующие показатели, которые характеризуют научно-исследовательскую деятельность:

- обладание источником финансирования, т.е. государственные контракты, гранты, хоздоговора;

- принятие участия в федеральных проектах, организуемых системой российского образования, на основе инициативного выполнения;

- тематика исследований, которая соответствует научному потенциалу университета;

- наличие молодых ученых в составе участников научно-исследовательской деятельности университета в целях обеспечения обновления кадров, как это требует современное общество;

— вовлечение студентов в научную работу — работа студенческого научного общества, а также научных кружков, проведение конкурсов научных работ для студентов;
- планирование научно-исследовательской деятельности университета, как текущей, так и на перспективу;

- применение новых информационных технологий в процессе управления и организации научно-исследовательской деятельности университета;

— востребованы ли результаты научной деятельности - оценка общества результатов научной деятельности, а также количество побед в конкурсах и олимпиадах;

- наличие сотрудничества с органами, осуществляющими управление образованием, общественными и научными организациями, а также вузами [1].

На основании выше проведенного анализа можно сказать, что в российской практике существуют различные подходы к оценке научно-исследовательской деятельности университета, но ориентироваться следует на утвержденную официальную оценку, разработанную Департаментом государственной политики в сфере высшего образования и молодежной политики.

В табл. 2 представлены показатели оценки научно-исследовательской деятельности университета, используемые различными авторами.

Методы оценки управления научноисследовательской деятельностью, используемые в мировой практике. В мировой практике применяются также различные методы оценки деятельности университетов. Рассмотрим некоторые из них [4].

Таблица 2

\section{Показатели оценки научно-исследовательской деятельности разных авторов}

\begin{tabular}{|l|c|c|c|c|}
\hline \multicolumn{1}{|c|}{ Критерии } & \multicolumn{3}{c|}{ Авторы } \\
\cline { 2 - 6 } & {$[9]$} & {$[3]$} & {$[7]$} & {$[1]$} \\
\hline Количество публикаций и цитирования в различных системах & + & + & + & - \\
\hline Объем НИОКР & + & + & + & - \\
\hline Число лицензионных соглашений & + & - & - & - \\
\hline Удельный вес молодых ученых & + & + & - & + \\
\hline НПР, защитившие кандидатские и докторские диссертации & + & - & + & - \\
\hline Количество грантов & + & + & - & + \\
\hline Деятельность по повышению научной квалификации & - & - & + & - \\
\hline Научно-исследовательская деятельность студентов & - & - & + & + \\
\hline Оценка результатов НИД обществом & - & - & - & + \\
\hline
\end{tabular}


Для примера возьмем опыт Великобритании. В Великобритании оценка управления осуществляется Королевской инспекцией и является строго централизованной. Это позволяет выполнять сравнительные оценочные мероприятия и в зависимости от рейтинга корректировать финансирование деятельности вузов, реализуемое государством. В стране применяется множество разных критериев оценки, но главными для вузов являются принятие участия в европейских и международных научных событиях, совершенствование и адаптация международных образовательных программ, а также аккредитация.

Рассмотрим еще один пример: в Нидерландах применяется циклическая система оценки, которая ориентирована на усовершенствование. Она содержит внутреннюю (самооценка и составление отчета о самоизучении) и внешнюю (деятельность инспектирующей комиссии по оценке качества и предоставление отчета в целях усовершенствования качества) составляющие. По результатам оценивания составляются отчеты, публикуемые в печати и в Интернете.

В Германии преобладает многоуровневая система оценки. Существует целый ряд аккредитационных организаций. Каждая организация предъявляет свой перечень требований по оценке качества деятельности университета и работает по собственным критериям, это позволяет университетам

Таблица 3

\section{Показатели оценки научной деятельности образовательных организаций в странах}

\begin{tabular}{|c|c|c|c|c|c|c|}
\hline \multirow[b]{2}{*}{ Показатель } & \multicolumn{6}{|c|}{ Страна } \\
\hline & 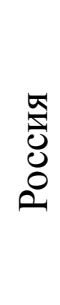 &  & 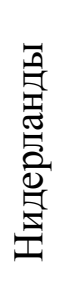 & 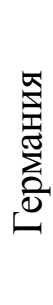 & 昰 & 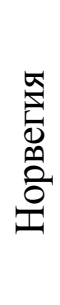 \\
\hline $\begin{array}{l}\text { Количество публикаций и цитирования в различных системах } \\
\text { страны }\end{array}$ & + & + & + & + & + & + \\
\hline Доходы от НИОКР в образовательной организации & + & + & + & + & + & + \\
\hline Количество полученных грантов образовательной организацией & + & + & + & + & + & + \\
\hline $\begin{array}{l}\text { Количество лицензионных соглашений, полученных образова- } \\
\text { тельной организацией }\end{array}$ & + & + & + & + & + & + \\
\hline $\begin{array}{l}\text { Количество и доля иностранных студентов, обучающихся в об- } \\
\text { разовательной организации }\end{array}$ & - & + & - & + & - & + \\
\hline $\begin{array}{l}\text { Удельный вес средств, полученных образовательной организаци- } \\
\text { ей от использования результатов интеллектуальной деятельности }\end{array}$ & + & + & + & + & + & + \\
\hline $\begin{array}{l}\text { Число патентов, изобретений, зарегистрированных в образова- } \\
\text { тельной организации }\end{array}$ & - & + & + & + & + & + \\
\hline $\begin{array}{l}\text { Количество преподавателей из разных стран, которые препода- } \\
\text { ют в образовательной организации }\end{array}$ & - & + & + & + & + & + \\
\hline $\begin{array}{l}\text { Число международных исследовательских проектов, в которых } \\
\text { участвует образовательная организация }\end{array}$ & - & + & + & + & + & + \\
\hline $\begin{array}{l}\text { Показатели, характеризующие место образовательной организа- } \\
\text { ции в национальных и международных рейтингах }\end{array}$ & - & - & + & + & + & + \\
\hline $\begin{array}{l}\text { Самооценка, проводимая образовательной организацией в части } \\
\text { научно-исследовательской работы }\end{array}$ & - & - & + & - & + & + \\
\hline
\end{tabular}


поддерживать квалификацию по устоявшимся требованиям, а также проводить активную работу по всем направлениям развития.

В Финляндии для получения оценки качества применяются методы внутренней оценки или самооценки, но также допускается нахождение внешних наблюдателей. Таким образом, оценка качества образования складывается из совокупности двух составляющих, которые контролируются Финским советом по оценке качества деятельности университетов.

В Норвегии условно процедуру оценки можно разделить на два этапа: сначала проводится оценка, а далее выполняется контроль и проверка данной оценки внешними организациями на предмет ее адекватности. Контроль над системой осуществляет Национальное агентство по обеспечению качества высшего образования (NOKUT). Наибольшее значение отводится самооценке учебного заведения.

В таблице 3 приведено сравнение показателей оценки научной деятельности в разных странах (официальные источники) и страны, которые их используют.

Из таблицы 3 можно выделить схожие показатели России и зарубежных стран. Такими являются количество публикаций и цитирования в различных системах, доходы от НИОКР, количество полученных грантов, количество лицензионных соглашений, удельный вес средств, полученных образовательной организацией от использования результатов интеллектуальной деятельности, и число патентов, изобретений. Данные показатели учитывают для оценки во всех рассматриваемых странах.

Количество и доля иностранных студентов учитывается не во всех странах. В России этот показатель не используется. Также в России не рассматривается показатель числа патентов и изобретений.

В зарубежных странах при оценке принимается в расчет количество преподавателей из других стран, в России данный показатель не учитывается. В России рассматриваются преподаватели по ученым степеням и по количеству защит диссертаций.

В зарубежных странах важным показателем является количество международных исследовательских проектов. В нашей стране нет такого показателя.
В Нидерландах, Германии, Финляндии и Норвегии учитывается место вуза в рейтингах. В Великобритании данный показатель не рассматривается, так как оценка в этой стране строгая и проводится Королевской инспекцией. В нашей стране также не учитывается данный показатель при оценке научной деятельности.

Стоит отметить, что в Нидерландах, Финляндии и Норвегии важную роль в оценке играет самооценка вуза. В России не используется данный показатель из-за сложности проведения субъективной самооценки.

Заключение. Таким образом, системы оценки научной деятельности в России и за рубежом имеют свои сходства и различия. В целом каждая система показателей по-своему является практичной и целесообразной. Но стоит отметить, что некоторые показатели зарубежной системы можно применить и в России, например, показатели, характеризующие место вуза в национальных и международных рейтингах. Также отметим, что и зарубежную систему можно дополнить показателями из российской системы оценки научной деятельности.

\section{Литература}

1. Быхтин О.В., Сапрыка В.А., Юркова О.Н. Применение социологического мониторинга при оценке научно-исследовательской деятельности университетов // Современные проблемы науки и образования. 2013. - №4.

2. Витвицкая Л. А. Развитие взаимодействия субъектов образовательного процесса университета: Автореф. дис. канд. пед. наук. Оренбургский гос. университет, Оренбург. 2015. - $40 \mathrm{c}$.

3. Ганичева A. B. Система управления вузом [Электронный ресурс] / А.В. Ганичева // Электронный научный журнал «Современные исследования социальных проблем». 2015. - №1 (09). - Режим доступа: www. sisp.nkras.ru.

4. Медведев Д. Н. Концептуализация феномена качества образования в контексте стратегии его обеспечения в высшей школе// Вестник Тамбовского университета. Серия: Гуманитарные науки. — 2016. - №7. C. $151-158$. 
5. Выходиева Е.А., Гусева М.Н., Мальишкин Н.Г. Управление НИД в вузе // Вестник университета. - 2015. - №9. - С. 130.

6. Киселева М.А. Модель управления научно-исследовательской деятельностью национальных исследовательских университетов// Обзорно-аналитический журнал, научнопрактический журнал. - 2019. - №5 (65). C. 11.

7. Князева И.В. Проблемные вопросы организации научно-исследовательской деятельности вуза и проведения процедуры государственной аккредитации [Электронный ресурс]. - Режим доступа: http://www. rusrand.ru/konfl/knyazeva.pdf.

8. Ларионова М.В. Сравнительный анализ опыта оценки исследовательского потенциала университетов // Вестник международных организаций. — 2011. - №1 (32). - С.4-28.

9. Сайт «Мониторинг эффективности деятельности организаций высшего образования» [Электронный ресурс]. — Режим доступа: http://indicators.miccedu.ru/monitoring/.

10. Сайт Федеральной службы государственной статистики РФ [Электронный ресурс]. — Режим доступа: https://www.gks.ru/.

\section{References}

1. Byhtin O.V., Sapryka V.A., Jurkova O.N. Primenenie sociologicheskogo monitoringa pri ocenke nauchno-issledovatel'skoj dejatel'nosti universitetov [Application of sociological monitoring in evaluating research activities of universities] // Sovremennye problemy nauki i obrazovanija [Modern problems of science and education]. - 2013. - №4.

2. Vitvickaja L.A. Razvitie vzaimodejstvija subektov obrazovatel'nogo processa universiteta: Avtoref. dis. kand. ped. nauk. Orenburgskij gos. universitet, Orenburg [Development of interaction of subjects of the educational process of the University: Ph. D. (Pedagogical) Thesis. Orenburg State University, Orenburg]. 2015. - 40 p.

3. Ganicheva A. V. Sistema upravlenija vuzom [Jelektronnyj resurs] [University management system] / A. V. Ganicheva // Jelektronnyj nauchnyj zhurnal «Sovremennye issledovanija social'nyh problem» [Electronic scientific journal «Modern research of social problems»]. 2015. — №1 (09). — URL: www.sisp.nkras.ru.

4. Medvedev D. N. Konceptualizacija fenomena kachestva obrazovanija v kontekste strategii ego obespechenija v vysshej shkole [Conceptualization of the phenomenon of quality of education in the context of the strategy of its provision in higher education] // Vestnik Tambovskogo universiteta. Serija: Gumanitarnye nauki [Bulletin of Tambov University. Series: Humanities]. — 2016. — №7. - Pp. 151-158.

5. VyhodcevaE.A., Guseva M.N., Maly$\operatorname{shkin} N$. G. Upravlenie NID v vuze [The office of the NID at the University] // Vestnik universiteta [Bulletin of the University]. — 2015. №9. - P. 130.

6. Kiseleva M.A. Model' upravlenija nauchno-issledovatel'skoj dejatel'nost'ju nacional'nyh issledovatel'skih universitetov [Model for managing research activities of national research universities] // Obzorno-analiticheskij zhurnal, nauchno-prakticheskij zhurnal [Review and analytical journal, scientific and practical journal]. — 2019. — №5 (65). — P. 11.

7. Knjazeva I.V. Problemnye voprosy organizacii nauchno-issledovatel'skoj dejatel'nosti vuza i provedenija procedury gosudarstvennoj akkreditacii [Problematic issues of organizing research activities of the University and conducting the state accreditation procedure] [Jelektronnyj resurs]. — URL: http://www.rusrand. $\mathrm{ru} /$ konfl/knyazeva.pdf.

8. Larionova M. $V$. Sravnitel'nyj analiz opyta ocenki issledovatel'skogo potenciala universitetov [Comparative analysis of the experience of evaluating the research potential of universities] // Vestnik mezhdunarodnyh organizacij [Bulletin of international organizations]. 2011. — №1 (32). — Pp. 4-28.

9. Sajt «Monitoring jeffektivnosti dejatel'nosti organizacij vysshego obrazovanija» [Website «Monitoring the effectiveness of higher education organizations»] [Jelektronnyj resurs]. - URL: $\mathrm{http} / /$ indicators.miccedu.ru/monitoring/.

10. Sajt Federal'noj sluzhby gosudarstvennoj statistiki RF [Website of the Federal state statistics service of the Russian Federation] [Jelektronnyj resurs]. — URL: https://www.gks.ru/. 




Кетоева Наталья Леонидовна - кандидат экономических наук, доцент кафедры «Менеджмент в энергетике и промышленности» Национального исследовательского университета «МЭИ». Научные интересы: управление персоналом, управление научной и образовательной деятельностью университета, энергетика.

Ketoeva Natalia Leonidovna - Candidate of Economic Sciences, Associate Professor, Department of Management in Energy and Industry, National Research University «MPEI». Research interests: personnel management, management of scientific and educational activities of the University, energy.

143905, г. Балашиха, ул. 40 лет Победы, 29, кв. 43

2940 years of Victory, app. 43, 143905, Balashikha, Russia

E-mail: nh176@mail.ru



Киселева Мария Андреевна - старший преподаватель кафедры «Менеджмент в энергетике и промышленности» Национального исследовательского университета «МЭИ». Научные интересы: управление персоналом, управление научной и образовательной деятельностью университета.

Kiseleva Maria Andreyevna - Senior Lecturer, Department of Management in Energy and Industry, National Research University «MPEI». Research interests: personnel management, management of scientific and educational activities of the University.

109147, г. Москва, ул. Марксистская, 5, кв. 275

5 Marxistskaya st., app. 275, 109147, Moscow, Russia

E-mail: goldenrose.91@mail.ru

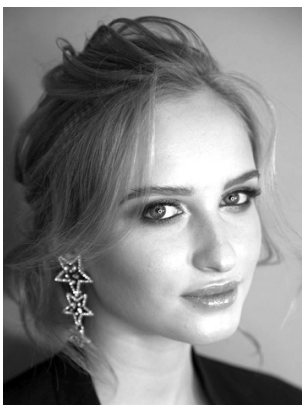

Котельная Виктория Константиновна - магистрант 1-го курса кафедры «Менеджмент в энергетике и промышленности» Национального исследовательского университета «МЭИ».

Kotelnaya Victoria Konstantinovna - 1st year master's student, Department of Management in Energy and Industry, National Research University «MPEI».

141135, Московская обл., Щелковский р-н, д. Малые Петрищи, ул. Луговая, 6 6 Lugovaya st., 141135, Malye Petrishchi, Shchelkovsky dist., Moscow reg., Russia E-mail: kvk1996@mail.ru 